not have to pay for the camera or editing facilities. We have decided to charge $£ 40$ per VHS copy. This amount covers the . copying cost and postage, leaving a little spare to fund future productions. The time involved in making the programme has not been taken into account.

I feel that such expenditure is fully justified: in spite of high academic levels of achievement now required for entry to medical school, students still differ in ability to understand new concepts. Videotaped programmes from all sources provide a substantial reservoir of teaching material to complement traditional teaching methods. A natural repository for such material is the library. At St George's we now have two replay monitors and VHS machines. For small screens VHS provides a perfectly satisfactory picture and has the advantage that tapes and machines are one third the cost of the Umatic equivalent. The equipment is discreetly bolted down and the tapes are security tagged. We have not had any problem with misuse or theft. I had originally thought that the students would watch the programmes individually but in the event they often watch in groups of two or three. At the moment headphones are provided but ideally each machine should be in its own room. It has been difficult to find suitable titles for the library. The British Universities Film and Video Council produce a catalogue with over 5,500 titles and I have found them very helpful.
When students join the psychiatric firm they are given a handout with a few lines on each title. Some programmes are regularly used in seminars and this is indicated on the handout. 'Psychological Defence Mechanisms' comes into this category. We hope that students will tailor their learning to meet their own needs and will also use the tapes for revision.

In the future, co-operation between medical schools would be beneficial. The cost of programme production is substantial yet this cannot really be met from sales. The taxpayer, who ultimately foots the bill, will at least expect the programmes to be used widely. In the past inter-school projects have floundered as a result of parochial interests. Even with 'Psychological Defence Mechanisms', I know that not everybody agrees wholeheartedly with the message in every single scene! However, at least in psychiatry there is little resistance to using a programme produced by another medical school.

Video is here to stay and there are exciting developments for the future. Equipment is becoming smaller, cheaper, more robust and technically better. However, emphasis must be on quality 'software'. At the moment, throughout the country there are miles of videotaped patient interviews that are unedited, unwatched and unusable. Little wonder that enthusiasm has waned.

At the bottom line a University is about education and video can often be the best way of getting the message across.

\title{
The Use of the Telephone in Continuing Psychiatric Education: Successes and Failures
}

\author{
C. P. Seager, Professor of Psychiatry, Department of Psychiatry, University of Sheffield.
}

To those who have bought shares in British Telecom, and for those who have not, this report may offer evidence to help them rationalize their judgement about the wisdom of their action.

Lester' has reviewed the literature on telephone communication for patients in psychotherapy and points out that it can be the communication method of choice for certain patients, although therapists may find it a major disadvantage in so far as it offers ready accessibility at times inconvenient to the therapist. The telephone has also been used as a method of distance learning, particularly by the Open University. It offers the opportunity of communication between a tutor and his students where distance prevents ready access. The Centre for Medical Education, Dundee, has regular telephone topics of interest to general practitioners, but these are not problemrelated.

This report deals with three different ways in which telephone communication has been used to promote aspects of Continuing Medical Education in the field of psychiatry. The first of these, Quip (Questions in Psychiatry), offered an opportunity for general practitioners to phone in with questions concerning their psychiatric problems. Parry 2 pointed out that Continuing Medical Education for general practi- tioners needed to be immediate, appropriate and relevant to the particular problem with which the family doctor was dealing at the time. If the problem was one of paediatrics there was no advantage in attending a lunch-time seminar on management of elderly demented patients.

The Department of Psychiatry at Sheffield University, with the help of Upjohn Limited, organized a telephone answering machine attached to a dedicated telephone line to which general practitioners could ring in and put their questions on the machine and have them answered within 24-48 hours by members of the Department, including honorary lecturers (NHS consultants), who agreed to participate in the service.

General practitioners were circulated with information about the service together with the telephone number on small adhesive labels which could be put in a prominent place on the desk, by the telephone or in the visiting diary.

The service opened with the arrival of the first telephone call, not from a general practitioner but from a patient. This patient was in tears because her general practitioner had prescribed potassium clorazepate (Tranxene) three times daily while she was under the impression that the normal dose was once daily. Her general practitioner evidently insisted that he was giving the right dose and when she continued to 
question it he gave her the telephone number of the service and told her to ring up and check. A further five telephone calls occurred, one from a general practitioner asking a question about personal symptoms, another almost incoherent question which may have been from someone under the influence of alcohol and two or three silences following the tone of the telephone machine. All these occurred in the first two or three weeks of the service and no questions were subsequently received. This experiment must be considered to have failed.

An obvious conclusion to be drawn was that the service did not meet the needs of general practitioners. This may be because there are relatively few psychiatric questions for which the general practitioner requires an answer in this way. If there are, they could be answered direct by a telephone call to an individual psychiatrist. The information may not have been conveyed appropriately to the family doctors or was, perhaps, forgotten by the time the question came to mind. One can also be cynical and say that no lunch or alcohol accompanied the answer to the questions!

The second experiment involved a Royal College of Psychiatrists Working Party on Management Training. This was set up by Council to examine the need for management training for consultants and trainees. It consisted of four College members and the Secretary of the College. They met in Belgrave Square on two occasions and produced a draft document. This was circulated and corrected. Instead of gathering for a third meeting, the process was carried out by telephone. Thus three speakers in different parts of London, one in Bristol and one in Sheffield were able to talk for 20 minutes working their way through the document paragraph by paragraph correcting various points. It was a very much shorter and more effective way of correcting the draft than visits to a central meeting place which would have involved four to five hours' journey time for at least two of the participants. The total cost to the College was $£ 8$ in addition to the 20 minutes spent by each individual.

This mode of working would probably be most appropriate for reviewing a previously circulated draft document. It has not been tried as yet for the initial meeting where ideas are discussed and where time spent is likely to be longer and discussions are less controlled. With a firm chairman who ensures that each speaker has an opportunity to put a point of view clearly, this method of communication obviously has considerable time and financial implications.

The third venture involved an educational meeting for general practitioners and psychiatrists held at the Medical School at Sheffield University. Fifty doctors gathered to listen to the three lectures on various psychiatric subjects. The first of these was delivered in the conventional manner by a speaker at the meeting. The remaining two lectures were delivered by speakers in their own homes talking into the telephone and amplified so that it could be clearly heard by the audience. The project was funded by Messrs Merck who arranged for the installation of the telephone line and the loudspeaker equipment, as well as inviting the speakers. At the end of the meeting the audience were asked their opinion about the efficacy of this method of postgraduate education. In general, there was considerable support for the telephone speakers as well as for the person who actually attended the meeting.

Points which were raised concerning the 'distance' speakers were that it would be helpful to have a photograph of the speaker projected to give some body to the voice; showing slides during the lectures was noted to be an advantage. One speaker did show slides which he had sent to the meeting beforehand, while the other did not, and this made for a rather less focused lecture. One difficulty which arose was that because there was only a chairman's microphone, questions had to be relayed to the speakers via the chairman, whereas it would have been much more convenient to have transmitted the questions directly to the speakers at home by use of a roving microphone. The two speakers were not in contact with each other although they could have been if they had wished to listen to each other's topics. These talks were on entirely different subjects, but speakers on associated subjects may well prefer to hear what other speakers have been saying.

In the field of psychiatry, as in other subjects, there is often a problem of small audiences being deprived of the opportunity of visiting speakers, particularly if they are geographically isolated. One solution is to send a video tape, but this means that there can be no discussion with the speaker. The telephone conference does offer an opportunity of immediate contact together with discussion at the end of the lecture: a video line would have improved contact even more, but is considerably more expensive. It should also be pointed out that the one-off aspect of the present meeting made it more expensive than having an established telephone line and loudspeaker system, as is available in some departments.

One speaker regretted the opportunity of not visiting the Outer Hebrides for postgraduate lectures and the associated non-educational delights of the environment, and this may be an important factor in deciding in favour or otherwise of this mode of communication.

\section{REFERENCES}

ILESTER. D. (1977) The Use of Alternative Modes for Communication in Psychotherapy. Springfield, Illinois: Charles $\mathrm{C}$. Thomas.

2PARRY, K. M. (1983) Paper presented at a conference of the Association of Medical Education in Europe (AMEE) in Prague.

\section{Confidentiality and Forensic Psychiatry}

The Forensic Psychiatry Specialist Section has prepared a document entitled 'Confidentiality and Forensic Psychiatry', which deals with the special difficulties in relation to confidentiality confronting those working in a forensic setting. Any member wishing to obtain a copy of this document should write to the Secretary, The Royal College of Psychiatrists, 17 Belgrave Square, London SW1X 8PG. 